\title{
Brain Acetylcholine in Morphine Pellet Implanted Rats Given Naloxone*
}

\author{
EDWARD F. DOMINO and ANN E. WILSON \\ Department of Pharmacology, The University of Michigan \\ Ann Arbor, Michigan
}

Received February 19, 1974

\begin{abstract}
Adult male rats were implanted with intraventricular (ivt.) brain cannulae for injection of $5 \mu \mathrm{g}$ of acetylseco-hemicholinium-3 (acetylseco $\mathrm{HC}-3$ ) as a means of studying acetylcholine $(\mathrm{ACh})$ utilization during morphine withdrawal. Animals were made dependent by implanting s.c. two $75 \mathrm{mg}$ morphine base pellets $24 \mathrm{hrs}$ apart. On the 4th day animals were given $10 \mathrm{mg} / \mathrm{kg}$ of naloxone i.p. and/or $5 \mu \mathrm{g}$ acetylseco $\mathrm{HC}-3$ ivt. and sacrificed by decapitation at various times. The brains were removed and assayed for
\end{abstract}

ACh using a pyrolysis gas chromatographic procedure. Total brain ACh before or after acetylseco-HC-3 was not altered at $5,30,60$ and 120 but was decreased at $10 \mathrm{~min}$ after naloxone. These results are in sharp contrast to our previous data of enhanced brain ACh utilization in withdrawn rats made dependent to morphine by several weeks of twice daily injections. It is apparent that short term morphine pellet administration does not produce the marked neurochemical and behavioral changes of long term morphine injections.

Key words: Acetylcholine - Acetylseco-Hemicholinium - Morphine - Naloxone.

The pellet method of studying morphine tolerance and withdrawal is now widely used because of rapidity of tolerance development and obvious convenience to investigators (Way et al., 1969; Wei, 1972). Recently, Cheney and Hanin (1973) reported that acute morphine administration reduced mouse brain acetylcholine $(\mathrm{ACh})$ turnover. They were able to show rapid tolerance development to this phenomenon in morphine pellet implanted animals. Their elegant studies of brain ACh turnover confirmed our previous findings (Domino and Wilson, 1973a) in the rat using indirect means of measuring $\mathrm{ACh}$ utilization via intraventricular (ivt.) hemicholinium-3 (HC-3) induced $\mathrm{ACh}$ depletion and its antagonism by morphine and other narcotic agonists. We also reported that during morphine withdrawal in dependent rats previously given the drug bid for 8-12 weeks there was increased utilization and a decrease in total brain ACh (Domino and Wilson, 1973b). Using a different approach Large and Milton (1970) came to a similar conclusion. Recently, Bhargava and Way (1974) showed that brain ACh is reduced in morphine pellet treated mice and rats given naloxone, and that the $\mathrm{ACh}$ decrease was associated with increased jumping during with-

* Supported in part by grant DA 00830, USPHS. drawal. Hence, it was quite surprising that Cheney and Hanin were unable to show any change in brain ACh turnover in morphine pellet implanted mice 15 min after naloxone injection. We argued that one must study the complete time course of narcotic withdrawal for a biphasic effect on ACh release is known to occur (Labrecque and Domino, 1973). Thus, 15 min may be the critical inflection point for no change in $\mathrm{ACh}$ turnover. Nevertheless, the Cheney and Hanin study was sufficiently disturbing to cause us to reexamine the problem in morphine pellet rats using those techniques of ACh utilization with which we are familiar.

The present manuscript describes findings in the rat which are similar to those obtained by Cheney and Hanin, as well as Bhargava and Way in the mouse and rat. However, our data raises serious questions regarding the significance of short term morphine pellet implantation as a means of studying morphine dependence.

\section{Methods}

Male Holtzman rats $250-300 \mathrm{~g}$ were housed 6 to 10 in group cages under previously described conditions (Domino and Wilson, 1973a, b). Rats were used one week after implantation with ivt. polyethylene cannulas by the method of Robinson et al. (1969) and Altaffer et al. (1970). Rats receiving 
morphine ( $75 \mathrm{mg}$ base) pellets were implanted 3 days prior to use by the method of Wei (1972). Two pellets were implanted $24 \mathrm{hrs}$ apart. In one series the pellets were not removed and during another they were removed $6 \mathrm{hrs}$ prior to withdrawal. Withdrawal was precipitated by $10 \mathrm{mg} / \mathrm{kg}$ of naloxone hydrochloride i.p. calculated as base. Acetylseco hemicholinium-3 (acetylseco $\mathrm{HC}-3$ ) was given to unanesthetized slightly restrained rats via the ivt. cannula $1 / 2 \mathrm{hr}$ prior to sacrifice. All animals were guillotined at approximately the same time (8:00-9:00 a.m.) each day. Rat brain ACh was determined by gas liquid chromatography per the methods of Schmidt et al. (1972) and Szilagyi et al. (1972). After guillotine, brains were removed and homogenized in acetonitrile with $25 \mathrm{nmol}$ of proprionylcholine as internal standard. A Hewlett Packard 5750 gas chromatograph with $8 \mathrm{ft}$. by $1 / 4$ in. stainless steel columns packed with $20 \%$ Carbowax 6000 on $60 / 80$ mesh Chromasorb W (HMDS) was used for analysis.

\section{Results}

In Table 1 are given mean brain $\mathrm{ACh} \pm \mathrm{S}$. E. in $\mathrm{nmol} / \mathrm{g}$ wet weight after various procedures.It should be noted that mean brain $\mathrm{ACh} \pm \mathrm{S}$. E. of control animals was $18.1 \pm 1.3$ with the Schmidt $e$ t al. procedure and 24.6 \pm 0.7 with the Szilagyi $e t$ al. procedure. Rats which received no treatment of any kind did not significantly differ in brain ACh from those that were cannulated, contained morphine pellets for $72 \mathrm{hrs}$ or sham pellet rats that received $10 \mathrm{mg} / \mathrm{kg}$ naloxone $1 / 2 \mathrm{hr}$ prior to sacrifice. The ivt. injection of $5 \mu \mathrm{g}$ of acetylseco HC-3 to control animals caused a significant decrease in brain ACh to $10.1 \pm 0.6 \mathrm{nmol} / \mathrm{g}$. This dose of acetylseco HC-3 was chosen because it gave a moderate depletion of rat brain $\mathrm{ACh}$ which could be used as an indirect indicator of $\mathrm{ACh}$ utilization (Domino and Wilson, $1973 \mathrm{a}, \mathrm{b}$ ). Mean brain $\mathrm{ACh} \pm \mathrm{S}$. E. at various times of withdrawal with and without $5 \mu \mathrm{g}$ ivt. acetylseco HC-3 are also given in Table 1 . When $72 \mathrm{hrs}$ morphine pellet rats received $10 \mathrm{mg} / \mathrm{kg}$ naloxone there was no significant change in brain $\mathrm{ACh}$ at $1 / 2 \mathrm{hr}$ whether the pellet was present or had been removed $6 \mathrm{hrs}$ previously. During the first $4 \mathrm{~min}$ after naloxone animals exhibited exploratory behavior, wet shakes, blanching of ears and tachypnea. A marked sedation was observed 5-8 min later with diarrhea, vocalization on touch, rhinorrhea and ptosis. Morphine pellet rats given $5 \mu \mathrm{g}$ ivt. acetylseco $\mathrm{HC}-3$ in addition to naloxone exhibited similar signs. Brain ACh was decreased but not significantly above or below levels of brain ACh after $5 \mu \mathrm{g}$ of ivt. acetylseco $\mathrm{HC}-3$ given alone to control animals. Only $10 \mathrm{~min}$ after naloxone was there a significant decrease in brain $\mathrm{ACh}$ in the morphine pellet animals.

Table 1. Mean brain ACh \pm S.E. nmol/g

\begin{tabular}{|c|c|c|c|c|c|c|}
\hline \multirow[t]{2}{*}{ Treatment } & \multicolumn{3}{|c|}{ Alone } & \multicolumn{3}{|c|}{ Plus $5 \mu \mathrm{g}$ ivt. acetylseco $\mathrm{HC}-3$} \\
\hline & $N$ & & $\begin{array}{l}\text { A } \\
p \text { value }\end{array}$ & $N$ & & $\begin{array}{l}\mathrm{B} \\
p \text { value }\end{array}$ \\
\hline \multicolumn{7}{|l|}{ Schmidt et al., ACh assay } \\
\hline Controls & 13 & $18.1 \pm 1.3$ & NS & - & - & NS \\
\hline Morphine pellet ( $72 \mathrm{hrs}$ ) & 8 & $18.4 \pm 0.7$ & NS & - & - & NS \\
\hline Cannulated rats & 8 & $18.2 \pm 0.4$ & NS & 9 & $10.1 \pm 0.6$ & $<0.001$ \\
\hline Sham pellet, $10 \mathrm{mg} / \mathrm{kg}$ naloxone & 8 & $18.6 \pm 0.3$ & NS & 7 & $10.1 \pm 0.3$ & $<0.001$ \\
\hline $\begin{array}{l}\text { Sham pellet, } 10 \mathrm{mg} / \mathrm{kg} \text { naloxone pellet removed } \\
1 / \mathrm{hr} \text { withdrawal, } 10 \mathrm{mg} / \mathrm{kg} \text { naloxone pellet }\end{array}$ & 8 & $17.7 \pm 0.9$ & NS & & & \\
\hline $\begin{array}{l}\text { not removed } \\
1 / 2 \mathrm{hr} \text { withdrawal, } 10 \mathrm{mg} / \mathrm{kg} \text { naloxone pellet }\end{array}$ & 17 & $18.9 \pm 2.4$ & NS & 9 & $11.2 \pm 0.5$ & $<0.001$ \\
\hline $\begin{array}{l}\text { removed } \\
\text { remal, } 10 \mathrm{mg} / \mathrm{Kg} \text { naloxone pellet }\end{array}$ & 8 & $16.4 \pm 0.5$ & NS & & & \\
\hline $1 \mathrm{hr}$ withdrawal, $10 \mathrm{mg} / \mathrm{kg}$ naloxone pellet & 8 & $19.6 \pm 0.7$ & NS & 8 & $10.1 \pm 0.4$ & $<0.001$ \\
\hline $\begin{array}{l}2 \text { hrs withdrawal, } 10 \mathrm{mg} / \mathrm{kg} \text { naloxone pellet } \\
\text { not removed }\end{array}$ & 8 & $18.6 \pm 1.1$ & NS & 7 & $11.0 \pm 0.4$ & $<0.001$ \\
\hline \multicolumn{7}{|l|}{ Szilagyi et al., ACh assay } \\
\hline $\begin{array}{l}\text { Controls } \\
5 \mathrm{~min} \text { withdrawal } 10 \mathrm{mg} / \mathrm{kg} \text { naloxone pellet }\end{array}$ & 7 & $24.6 \pm 0.7$ & NS & 14 & $14.2 \pm 0.5$ & NS \\
\hline 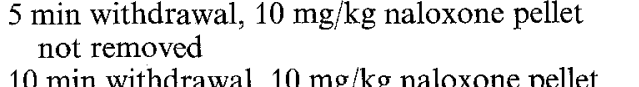 & 8 & $23.5 \pm 0.6$ & NS & 7 & $13.1 \pm 0.6$ & NS \\
\hline $\begin{array}{l}10 \text { min withdrawal, } 10 \mathrm{mg} / \mathrm{kg} \text { naloxone pellet } \\
\text { not removed }\end{array}$ & 8 & $21.6 \pm 0.7$ & $<0.05$ & 9 & $14.0 \pm 0.6$ & NS \\
\hline
\end{tabular}

A Group comparison Student " $t$ " tests of appropriate control vs withdrawn rats.

B Group comparison Student " $t$ " tests of alone vs rats with $5 \mu \mathrm{g}$ ivt. acetylseco HC-3. 


\section{Discussion}

The rat brain ACh levels of pellet animals during morphine withdrawal differ considerably with those we found in withdrawing rats given weeks of morphine by injection (Domino and Wilson, $1973 \mathrm{a}, \mathrm{b}$ ). Instead of a decrease, there was no change in the morphine pellet present or the morphine pellet absent animals 5, 30, 60 and $120 \mathrm{~min}$ after naloxone. Only $10 \mathrm{~min}$ after naloxone were total brain $\mathrm{ACh}$ levels reduced in the morphine pellet animals $(P<0.05)$. There was no significant change in brain ACh utilization as measured indirectly by acetylseco $\mathrm{HC}-3$. The morphine pellet present or absent rats given naloxone showed obvious withdrawal since their signs corresponded to those described by Wei (1972). Rats did not show any withdrawal symptoms $6 \mathrm{hrs}$ after pellet removal. The major deficiency of this study was our failure to quantify the degree of morphine withdrawal the animals were experiencing. This is especially critical in view of the observation by Bhargava and Way (1974) that only rodents which jumped during morphine withdrawal showed decreased brain ACh levels.

Naturally withdrawn rats after weeks of a narcotic agonist show an increase in motor activity (Akera and Brody, 1969; Martin et al., 1963). On the other hand, rats tolerant to morphine via injection or pellet implantation given a narcotic antagonist show immobility (Kaymakcalan and Woods, 1956; Large, 1972; Wei, 1972 ) with return to normal activity. Rats undergoing withdrawal after weeks of a narcotic agonist experience prolonged stress. In our morphine pellet animals at the end of $2 \mathrm{hrs}$ of withdrawal there was a 6-8\% weight loss. In our naturally withdrawn chronically treated rats there was a $14-20 \%$ weight loss after 48 hrs. Akera and Brody (1969) have noted that at $48 \mathrm{hrs}$ withdrawal symptoms were most prominent in such chronic morphine dependent animals. Tilson et al. (1973) have also described the greatest decrease in nociceptive threshold at this time.

It should be noted that Colasanti et al. (1974) found that $72 \mathrm{hrs}$ morphine pellet implanted rats upon removal of the pellets show much shorter rebound REM sleep time during abstinence than after prolonged i.v. morphine (Khazan and Colasanti, 1972). These investigators concluded that their i.v. method produces a greater degree of drug dependence. Recently, Bläsig et al. (1973) have studied the development of physical dependence on morphine in rats implanted s.c. with morphine containing pellets in which the dosage, frequency of implantation, and duration of exposure to morphine were varied. These investigators showed that the various signs of precipitated withdrawal do not all increase concomitantly with increasing dependence. It is therefore quite possible that observed changes in ACh turnover are associated with the manifestation of a particular behavior rather than an underlying physiological mechanism relevant to physical dependence per se.

It appears that morphine withdrawal after pellet implantation, while producing many of the physical signs of withdrawal, does not affect brain ACh similar to rats receiving morphine over many weeks. The symptoms are on entirely different time scales and much more compressed in the pellet withdrawing rats. In addition, dependent rats given morphine by injection show excitation immediately after the morphine. Such rats subjected to prolonged exposure to morphine, whether withdrawal is by an antagonist or naturally, have different brain levels of ACh than pellet withdrawing animals given an antagonist. Large (1972) found that nalorphine precipitated abstinence in tolerant rats may be manifested by either excitement or depression, depending on frequency of injection, the strain of the rats, whether they received a regular dose of morphine before the antagonist, or when the antagonist was used in place of the morphine. Chronic exposure to a narcotic agonist undoubtedly causes biochemical and physiological changes that do not have time to occur in the 3 day morphine pellet rats. Thus, the method used to produce physical dependence to narcotics and the manner in which withdrawal is precipitated should be carefully considered. The changes that occur in brain ACh content and turnover are on different time scales, intensities, and can be in opposite directions. Furthermore, it is not valid to make comparisons between two modes of drug administration when drug dosages, brain levels, and time course are not comparable. Obviously such studies need to be done. The present results merely emphasize the need for more careful investigations and caution the indiscriminant use of morphine pellets without such quantitative data.

\section{References}

Akera, T., Brody, T.M.: The addiction cycle to narcotics in the rat and its relation to catecholamines. Biochem. Pharmacol. 17, 675-688 (1969)

Altaffer, F. B., de Balbian, Verster, F., Hall, S., Long, C. J., D'Encarnocao, P.: A simple and inexpensive cannula technique for chemical stimulation of the brain. Physiol. Behav. 5, 119-121 (1970)

Bhargava, H. H., Way, E. L.: Morphine tolerance, dependence and withdrawal and brain acetylcholine. Pharmacolist 16, 260 (1974)

Bläsig, J., Hertz, A., Reinhold, K., Zieglglansberger, S.: Development of physical dependence on morphine in respect to time and dosage and quantification of the precipitated withdrawal syndrome in rats. Psychopharmacologia (Berl.) 33, 19-38 (1973) 
Cheney, D. L., Hanin, I.: Effect of acute and chronic morphine on specific radioactivity of choline and acetylcholine in mouse brain. Fed. Proc. 32, 757 (1973)

Colasanti, B., Kirchman, A., Khazan, N.: EEG and REM sleep in morphine abstinence rats: s.c. pellets vs. i.v. administration. (In preparation, 1974)

Domino, E.F., Wilson, A.E.: Effect of narcotic analgetic agonists and antagonists on rat brain acetylcholine. J. Pharmacol. exp. Ther. 184, 18-32 (1973a)

Domino, E.F., Wilson, A. E.: Enhanced brain acetylcholine utilization during morphine withdrawal in the rat. Nature (Lond.) 243, 285-286 (1973b)

Kaymakcalan, S., Woods, L.A.: Nalorphine-induced "abstinence syndrome" in morphine tolerant albino rats. J. Pharmacol. exp. Ther. 117, 112-116 (1956)

Martin, W. R., Wikler, A., Eades, C. G., Prescor, F. T.: Tolerance to and physical dependence on morphine in rats. Psychopharmacologia (Berl.) 4, 247-260 (1963)

Labrecque, G., Domino, E. F.: Liberation d'acetylcholine due neocortex du chat après administration aique et chronique de morphine. Annal de L'Association Candienne Française pour l'Avancement de la Science 40, 123 (1973)

Large, W. A.: Effects of morphine, morphine analogues and morphine antagonists on central and peripheral cholin- ergic systems. Doctoral Thesis, University of London 1972

Large, W. A., Milton, A. S.: The effect of acute and chronic morphine administration on brain acetylcholine levels in the rat. Brit. J. Pharmacol. 38, 451P-452P (1970)

Robinson, C. A., Hengeveld, C. A., de Balbian, Verster, F.: Improved polyethylene cannulation techniques. Physiol. Behav. 4, 123-124 (1969)

Schmidt, D. E., Speth, R. C., Welsch, F., Schmidt, M. S.: The use of microwave radiation in the determination of acetylcholine in the rat brain. Brain Res. 38, 377-389 (1972)

Szilagyi, P. I. A., Green, J.P., Brown, O.M., Margolis, S.: The measurement of nanogram amounts of acetylcholine in tissues by pyrolysis gas chromatography. J. Neurochem. 19, 2555-2566 (1972)

Tilson, H. A., Rech, R. H., Stolman, S.: Hyperalgesia during withdrawal as a means of measuring the degree of dependence in morphine dependent rats. Psychopharmacologia (Berl.) 28, 287-300 (1973)

Way, E. L., Loh, H. H., Shen, F.: Simultaneous quantitative assessment of morphine tolerance and physical dependence. J. Pharmacol. exp. Ther. 167, 1-8 (1969)

Wei, E.: Quantification of precipitated abstinence in morphine dependent rats. Fed. Proc. 31, 527 (1972)

Dr. E. F. Domino, Department of Pharmacology

University of Michigan, Ann Arbor, Michigan 48104, U.S.A. 